\title{
EFFICIENCY AND PUBLIC POLICY IN DEFENSE PROCUREMENT
}

\author{
Frederick T. MOORE*
}

I

Procurement and contracting by the Department of Defense with U.S. industry amounts to almost half of the total defense budget and on the other hand accounts for all or the major part of the business of many firms. ${ }^{1}$ Even small percentage savings in an expenditure level in the billions quickly add up to impressive dollar amounts. Whether and to what extent savings in procurement can be achieved depends on the relative efficiency of the procurement process and on the means available for improving it. The economic notion of efficiency has hardly been applied to defense procurement in a systematic way. There is a fairly widespread image of inefficiency-one marked by confusion or worse on the part of the government buyer as to what it is that he is to procure and large windfall profits by contractors who are nonetheless inefficient. There are even hints that bad faith is often involved. This image is unfortunate and largely false. It fails to distinguish those results that are chiefly due to the quite unique characteristics of the market for weapon systems and hence unavoidable in part from those that might be corrected by public policy. Too often it is assumed that some tinkering with the instruments of contracting can provide the necessary correctives, whereas in fact there are complex problems in the market structure that limit what can be accomplished in this way.

There are several important questions that underlie most of the discussion of efficiency in procurement. They are of interest both to the buyer and the sellers though often in different ways. What are the criteria by which to identify an efficient contractor? How do you measure efficient performance? What are appropriate incentives and rewards for superior performance? What institutional facts-oflife impede the achievement of the desired results? These and similar questions recur constantly, implicitly or explicitly, in the discussions. Another question that is not so frequently asked can be added. What structural characteristics of the market are conducive to efficient behavior?

This paper examines some aspects of the above questions. The discussion is in

* B.A. I94I, M.A. I94I, University of Wisconsin; Ph.D. I950, University of California. Lecturer, University of California, 1948-50. Professor, University of Illinois, 1950-5I. Esonomist, U.S. Department of Interior, I95x-53. Senior Economist, The RAND Corporation, I953 to date. Author, MrLITARY Procurement and Contracting: An Economic Analysis (The RAND Corporation, RM-2948, June, I962). Other publications on economic development, mineral economics, and econometric models.

The views expressed in this paper are those of the author. They should not be interpreted as reflecting the views of The RAND Corporation or the official opinion or policy of any of its governmental or private research sponsors. Papers are reproduced by The RAND Corporation as a courtesy to members of its staff.

${ }^{1}$ This paper is based in part on a report by the author, Moore, MrLItary Procurement aNd ConTRACTING: AN Economic ANalysis (The RAND Corporation RM-2948-PR, June x962). 
three parts: a first part that considers the structural characteristics of the market and the possibilities for effective competition; second, a discussion of firm behavior and market results; and third, some implications of these factors for changes in public policy in defense procurement.

\section{II}

The problems of government procurement are usually presented in the framework of government relations to the "defense industry." In fact there is no defense industry in the sense that there is a steel industry, a copper industry, or an automobile industry. These industries are relatively homogeneous; the firms produce products that are close substitutes for each other; the products are competitive and production, cost, and financial conditions are roughly similar, though they may vary depending on the degree of integration, the number and size distribution of firms in the industry, and so forth. The so-called defense industry is much more diffuse, is less homogeneous, and on an over-all basis is less competitive than any of the industries named.

In the period from the end of World War II to the present there have been some major changes in the largest contractors of the Department of Defense. During World War II four automobile and two steel companies were included among the twenty largest contractors; the largest single contractor, with eight per cent of all prime contract dollars, was an automobile company. By Ig6r the largest single contractor, also with eight per cent, was an aircraft and electronics firm that had integrated horizontally and vertically. ${ }^{2}$ In twenty years aircraft, missile, and electronic firms replaced automobile, steel, and chemical firms on the list of the largest defense contractors. Moreover, twenty-two of the firms on the list of the one hundred largest defense contractors in $196 \mathrm{I}$ were not on the list at all a year earlier in 1960 . Even among the top twenty, what would be the "giant" or dominant firms in most industries, there are significant shifts. Eight of those listed in $x 96 \mathrm{x}$ do not appear among the top twenty in World War II.

This degree of rapid entry to and exit from defense business is unmatched in any other industry in the economy. It is evidence of the high volatility of defense business. Firms are forced out of the industry as demand shifts from one program to the next; they enter as new programs shift these demands toward products or skills that they possess. There is no doubt that the volatility of defense procurement has an effect on the extent and type of competition that exists. Competition tends to be focused at a few key times in the procurement process; that fact raises certain special problems. This is a subject to which we will return shortly.

The list of the largest contractors can be broken down into more homogeneous groups in such a way that there is apparently effective competition within the group but not between groups. For example, it is common to combine the major aircraft and missile firms in one group, and the electronics companies in another

${ }^{2}$ Id. at rog-Io. 
group. Some groups are not well defined and overlap with others. This is true to some extent of the aircraft, missiles and electronic groups, for in the postwar period there has been a tendency for the large firms to diversify and to integrate horizontally and vertically; firms that were primarily airframe manufacturers have integrated their activities to include propulsion or electronic capability, and other firms have acquired capabilities in some major area of defense business. There is an overlap and a blurring of the distinctions among the groups.

Yet even within apparently homogeneous groups there may be quite imperfect competition. Consider the dozen major aircraft companies. Is there substantial competition among the firms in the group? There certainly is competition between some of the firms, particularly the larger ones, but Grumman and Republic, for example, are really not serious competitors to Boeing and General Dynamics, especially in the large programs such as boosters. There is fragmentation of the market and attenuation of competition within groups. This does not mean, necessarily, that there is a lack of effective competition; to reach a conclusion on that score requires examination of additional elements of the market. It does mean that in the defense business there are a number of separate groups with little or no competition between them. They only compete for a share of the dollars spent on defense and while that is an important aspect to the Department of Defense in allocating its budget, it is relatively unimportant in the consideration of the effectiveness of competition.

The diversity of the items procured and the complexity of many of them naturally leads to a fragmentation of the market and limits competition to relatively small groups; but it is the pervasive quality of uncertainty that puts a unique stamp on defense procurement, that shapes many of the market results, and that affects the choice of public policy. The importance of this factor cannot be over-emphasized. There are uncertainties with respect to demand, cost, and technical elements, and all of them have a profound effect on the market.

Defense procurement is characterized by rapid changes in demand resulting from technological change or exogenous forces. Technological change leads to a great deal of uncertainty in individual programs. Missiles begin to replace manned aircraft, and a new generation of missiles supplants the last. Individual programs and contracts can be stretched out, speeded up, cut back, or terminated. Program uncertainty is an inherent part of the defense business.

As a general rule it is uncommon to find the demand for a commercial product (say, automobiles, refrigerators, or typewriters) varying in a short space of time from zero to some large number and then back to zero; commercial demand is more regular and continuous. Even the less efficient firm can usually count on some demand for its products. A firm's share of the market may decline-this is a typical sign of a poor competitive position-but rarely does its share drop precipitately to zero. The firm has time to adjust, to correct its mistakes, and to take a new course. Very seldom, even for durable goods, does the market become saturated or suddenly 
overtaken by technological change. Yet this does happen for defense products. Technological change is rapid; the market (as represented by a typical program) can grow rapidly and contract rapidly as programs are cut back and terminated. Shifts in defense demand are sudden and sometimes almost capricious. There are sufficient grounds to distinguish the uncertainties in the demand for defense products from the lesser uncertainties in the demand for commercial products. The consequences of demand uncertainty for defense products are reflected in the typical behavior of the Department of Defense. The tendency to allocate contracts so as to "keep in business" all of the major firms is in part the Department's recognition or acceptance of a responsibility to dampen the effects of these uncertainties.

It may be noted, however, that the government does assume some risks or responsibilities that in a normal business venture are assumed by the firm. First of all, procurement contracts often contain provisions for adjusting the contract price to the government for changes in prices of labor or major materials such as steel. There are instances in which a private firm can pass on price changes to the customer of course, but that normally cannot be done if the work is being done under a contract. The fact that the government quite commonly assumes an obligation to pay for such increases in costs removes a risk from the contractor.

Second, the government has since IgI6 supplied private firms with a large part of the plant and equipment needed for the production of defense products. At times whole plants have been built and equipped for the production of a single item; in a multi-plant firm in the aircraft industry it is common to find one or more plants wholly or in large part owned by the government and operated by the contractor, as well as one or more plants wholly or in large part owned by the contractor in which he may conduct commercial business.

In 1956 a calculation showed that the government had supplied the twelve large aircraft companies with $\$ 895,000,000$ in plant and equipment. The companies themselves owned $\$ 394,000,000$ in plant and equipment, "a large part of which represents reinvested profits." 3 Moreover, in I960, fifty-nine contractors having incentive contracts with the Air Force had the use of \$r.2 billion of government-owned plant and equipment, together with $\$ 2.0$ billion of company-owned assets representing for the most part reinvested profits from prior government contracts. In addition, some major facilities are almost entirely owned by the government. ${ }^{4}$

A further specific example may emphasize the point. The Boeing Airplane Company has been one of the main contractors for the Air Force for over a decade. In a case on profit renegotiation it was pointed out by the government that Boeing owned or leased only thirty-nine per cent of the plant that it used in 1952 for the production of B-47 aircraft, the remaining sixty-one per cent being supplied by the

\footnotetext{
${ }^{3}$ House Committee on Armed Services, Report on Aircraft Production Costs and Profits, 84th Cong., $2 \mathrm{~d}$ Sess. 3 III (x956).

4 Adapted from exhibits in Hearings Before the Special Subcommittee on Procturement Practices of the Department of Defense of the House Committee on Armed Services, Pursuant to Section 4, Public Lauv 86-89, 86th Cong., 2d Sess. App. 3, at 602-04 (1960).
} 
government. The $\$ 14,000,000$ that Boeing owned in fixed assets during $1952-53$ was only 1.9 per cent of its renegotiable sales ( $\$ 737.5$ million) and less than twenty-five per cent of its renegotiable profits $(\$ 56.7$ million) during $x 952$. Thus a very large volume of sales and a large profit were earned at the risk of a relatively small amount of fixed assets. ${ }^{5}$

The rationale for government supply of plant and equipment is primarily that it is required in order to get rapid expansion of output that is critically needed in the national defense. This implies that private industry would not, or could not, build such plants themselves or that it could be done only with greater delay. The government does not receive rent for the use of the facilities; but neither is a cost incurred by the government for the use of the plant such as would occur if the plant were privately owned. The one consideration is assumed to offset the other, but since the costs might be incurred at different times, it is not clear that the rent foregone is the exact equivalent of the cost not incurred. What is clear is that private industry does not risk as much capital as it otherwise would and does not face the uncertainty of future demand for products of that plant. The government assumes many of the risks of current and future demand changes.

A third element in the question of assumption of risk is in the provisions for working capital. The general and typical arrangement here is similar to that on fixed capital. The regulations provide that the government can make progress payments to a contractor during the course of the contract. These payments may be made for raw materials, work in process, or materials in transit so that, in effect, the government finances most of the inventories of the contractor. In fact, the government has made a point of excluding interest costs on working capital from costs payable under contracts and prefers to supply the working capital itself. As a result, the government has assumed a heavy commitment of funds for working capital in all of its major contracts. In the Boeing case just cited, the government furnished an average of more than eighty-seven per cent of the working capital required by the contractor during $1952 .{ }^{6}$ Thus, the risks and costs attendant on inventory financing or provision of working capital are likewise largely assumed by the government.

The record might be elaborated further with a discussion of risk allocation in other contractual elements, but let us simply take the ones we have. In the not-sohypothetical case of a firm which is supplied with over fifty per cent of its fixed capital, and up to ninety per cent of its working capital, and is guarded against price rises in labor and some materials, wherein lies the risk? It is only a partial answer to say that the risk lies in the possibility of losing money on the remainder of the cost elements not assumed by the government. Another possible answer is that, from the company's point of view, the risk lies in the possible failure of the corporate entity and loss of stockholders' equity or net worth. For a company whose total assets are devoted to defense business the termination of a major program may

\footnotetext{
${ }^{5}$ Brief for Respondent, Boeing Airplane Co., Petitioner, v. The Renegotiation Board of the United States, Respondent, in the Tax Court of the United States, Docket No. 935-R, pp. 69-70.

${ }^{6} I d$. at 72 .
} 
imperil the corporate life; but that is rare. Most companies do not have all their eggs in one basket.

Uncertainties on the demand side-program uncertainties-have a powerful effect on the market. They have in fact had the effect of modifying arrangements with respect to the allocation of risk so that the buyer (the government) assumes some of the risks of fixed and working capital that in a commercial market are assumed wholly by the seller. Consequently the incentives (profits or fees) should be modified accordingly to agree with the degree of risk. Alternatively the division of risk could be changed. One may question whether it is necessary for the government to provide fixed plant to contractors. The rationale for this provision in the past has been that it was a means to insure rapid production of necessary items. At the present time when reliance must be on forces-in-being, a program of governmentowned plants for post-attack production may well be obsolete.

Uncertainties are not limited to the demand side of the market. There are also significant uncertainties on the supply side. These arise because defense procurement is more and more in the nature of research and development; there are far fewer items now with long standardized production runs. The procurement of new weapons is different from the procurement of the commercial-type articles that the military buys. New weapons often push hard on the known state of the art. New components must be perfected and made to fit in the system. These and other similar factors make estimates of the cost, time of delivery, performance, ease of maintenance, reliability, and other characteristics of the system highly uncertain. A study made of cost estimates and delivery dates for a number of weapon systems compares final average costs to first average cost estimates and actual time to get an operational system to early estimates of the time. The study found that, on the average, final costs were seventy per cent higher than early cost estimates for fighters, I70 per cent higher for bombers, and 3ro per cent higher for missiles. Furthermore, the actual times required were forty per cent to 240 per cent greater than estimated, depending on whether a small or a large advance in the state of the art was sought.?

Variations in costs, delivery dates, performance, and so on may be attributable at times to deficiencies in the contractor, but for the most part they are due to inherent uncertainties in research and development. It is not possible to predict outcomes with any assurance. Predictions made early in the life of a new component or system will almost invariably turn out to be incorrect in some essential respects. The optimal system cannot be planned from the start, for as development proceeds, as experience and information are acquired, decisions previously made must be modified; the path to be followed is one involving a sequence of decisions and changes in the program. Unfortunately, changes are sometimes suggested and made for reasons not associated with the orderly development of the system. The

${ }^{7}$ Marshall \& Meckling, Predictability of the Costs, Time, and Success of Development, RAND Paper P-I82I, Dec. Ix, 1959 . 
objective should be to get a system ready for operational test and evaluation as quickly as possible, leaving till later many refinements. This in itself gives rise to all the uncertainties mentioned above; additional changes by the buyer or the seller simply add to the difficulties.

Supply uncertainties (in costs, performance, delivery dates, and so on) make it difficult to design effective incentive systems and in fact make it cumbersome to fit the contracting cycle to the milestones in a development program. These uncertainties involve risks to the contractor-risks of non-performance or not meeting objectives. Yet such risks are not borne wholly by the contractor. In many ways the government seeks to mitigate or to share some of the risk. On each contract or major program the government maintains a project staff that works directly with the contractor. The staff concerns itself with virtually all aspects of the operationquality control, system design, approval of subcontracting, and so on. By taking responsibility for daily decisions and by approving or disapproving major segments of the programs, the government in fact assumes responsibility for the risks involved. The allocation of risk between buyer and seller becomes blurred; it certainly does not resemble the allocation of risk in a normal commercial market and since it does not, the typical incentive and profit arrangements of a commercial market cannot or should not be applied in the same way to defense procurement. Because of the intimate intermingling of management responsibility in the programs, the government and the contractor are "dancing partners"; they are not conducting armslength buying and selling. Among other things this means that it is difficult to get a true test of the efficiency of contractors; it also means that tests of the willingness of contractors to accept high risks in the expectation of earning increased profit by superior performance are likely to be quite imperfect with present contractual arrangements.

One final factor affecting the market structure of the industry must be noted. There are a number of reasons for believing that total expenditures by the Department of Defense on major new systems will decline in the next few years. Much of the current level of expenditure is to complete programs that were started some time ago. Moreover, as has been mentioned above, the era of long production runs on major systems seems, by and large, to be over. There is a limited need for massive production lines and a greater requirement for specialized organization for research and development. As total expenditures shrink and as the emphasis on the type of work changes, it seems probable that the demand will be insufficient to support the existing number of major weapons contractors. There will be excess resources and capacity in the industry. In such a situation some resources inevitably must leave the market. This can occur through a failure of some firms or, more likely, through purchase of assets or merger of several firms.

There recently have been several major instances of actual or proposed mergerLing-Temco with Chance Vought; Ford absorbing Philco; McDonnell discussing merger with Douglas. In addition it seems very likely that within five years there 
will be mergers of several of the giants in the industry. The increased complexity of the problems, the greater demands on managerial and technical talents, and the lack of long sustaining production runs all contribute to the likelihood of mergers. Such a development poses special problems to the government.

The Department of Justice, applying the tests of the antitrust laws relating to mergers that diminish competition, would probably oppose such moves. But arguments can be produced showing that the rationalization of program management, the merging of skills, and additional economies in combining facilities and talents might lead to benefits to the Department of Defense. It is not simple to show that a merger diminishes competition (though there has been rather too quick an acceptance by the Department of Justice of the position that any reduction in the number of firms in an industry is prima facie evidence of a concomitant decrease in competition). Actually a case can be made for the position that a reduction in the number of aircraft companies (from twelve to six or seven) might lead to more effective competition, rather than less. In any event, the Department of Defense is very definitely a party in interest to such matters and would have to consider carefully what course to take.

One may draw several conclusions from this discussion of the market structure in defense procurement. The pervasiveness of uncertainty in both demand and supply has led to special arrangements between buyer and seller in the conduct of the business. The sharp distinctions in the risks that each party assumes in a typical commerical market are obscured; the government has assumed some risks normally assumed by the seller. It has also assumed responsibility for management decisions that normally are the province of the seller. The result is a mixing of the traditional roles and responsibilities of buyer and seller; and the result of that, in turn, means that it is difficult to test the efficiency of the contractor and to prescribe incentives that will reward superior performance. At best, there is a test of the joint abilities of the government and its contractors to carry out a program. Moreover, the shift to an emphasis on research and development activities means that effective competition is generally limited to the period when an award is to be made. Once that occurs both parties are essentially committed for some time to come; the risk of losing a major program once it is started is virtually nil. Finally, the structure of the industry is very likely to change over the next five years. This appears to be of two kinds; first, a reduction in the number of major weapons contractors (and probably in the total resources represented by them) and second, a greater integration and diversification in the activities of each major firm. Consequently the character of potential competition in the future will likewise change.

\section{III}

Efficiency in the use of resources and the record of performance in defense procurement are, however, of serious concern regardless of the problems that may arise over the longer run through basic changes in the structure of the industry. 
The two sets of problems are in fact interrelated. In judging the performance of an industry an economist commonly applies certain tests: the relationship of price to marginal cost, the level of profits, ease of entry to the market, the degree of progressiveness or innovation, and evidences of predatory market behavior. The performance of the group of major weapons contractors with respect to some of these factors must be considered.

Because of the emphasis on research and development and the lack of a standard product, the price-marginal cost comparison is almost impossible to make. This comparison is valuable since it shows the relationship between the price and the value of the resources needed to produce an additional product; the comparison thus indicates something about the effectiveness of competition and the efficiency of the producer in meeting competition. In defense procurement this comparison can only be approximated by observing the relationship of actual costs to the negotiated prices. An examination of cost behavior in defense contracts does reveal some interesting facts.

A sampling was made of two types of defense contracts-cost plus a fixed fee $(\mathrm{CPFF})$ and incentive (e.g., fixed price incentive fee). The latter involve setting a target cost and payment of an incentive fee for cost underruns of the target. The government and the contractor share the cost savings (or the overruns) on the basis of some percentage formula such as eighty per cent for the government, twenty per cent for the contractor. CPFF and incentive contracts are the two archetypes; the former represent the pure cost-type contract, and the latter are at the opposite end of the spectrum, since any cost saving accrues in part to the contractor. It should be noted that a fixed price contract is a special case of an incentive contract in which the sharing formula is o-roo per cent.

The sample consisted of $2,50 \mathrm{I} \mathrm{CPFF}$ contracts and 228 incentive contracts ranging in size from small contracts of under $\$$ I million to a few over $\$ 100$ million and covering a variety of contract work. The actual behavior of costs is easily summarized in the following numbers. ${ }^{8}$

$\begin{array}{ccc}\text { Per Cent of Time } & \text { CPFF } & \text { Incentive } \\ \text { a. Underrun } & 46 & 74 \\ \text { b. Overrun } & 54 & 26\end{array}$

For certain technical reasons it is possible that the CPFF data are biased and understate the extent of cost overruns, yet twenty-two per cent of the time final costs were more than double the original costs and in ninety-one cases the costs were increased more than ten times! This simply confirms what is well-known about CPFF contracts, that there is a strong tendency for costs to escalate without detriment to the fee; in fact, the fee may escalate more than cost. There is almost no chance for the operation of incentives to produce efficiency by the contractor in a CPFF contract.

\footnotetext{
${ }^{8}$ MoORE, op. cit. supra note $\mathrm{I}$, at $4 \mathrm{I}-49$.
} 
The (proportionately) much higher per cent of underruns in incentive contracts does not necessarily mean greater efficiency by contractors. This result may be due to poor estimation of the target cost such that it is easy to underrun the target and thus share in an apparent cost "saving"; nevertheless, the presumption is that the incentive feature leads firms to be more efficient. Firms normally react positively to the possibilities of increased profits and try to reduce costs to raise profits. A simplified theory of firm behavior advances the notion that firms try to maximize profits over some period of time. Although there is some truth in the proposition, it is much too simple. Firms act from many motives-the motive to survive in the market is a basic one; others include maintaining or increasing their share in the market, diversifying activities to broaden the product base and to raise safety margins. In fact, the tendency to play safe is frequently strong and will cause a firm to choose a course of action that yields a lower profit rather than another course of action that holds promise of a higher profit but with a much higher risk attached to it. In negotiating incentive contracts containing performance requirements with industry, it is fairly common to find that the engineering and technical staff are willing and even eager to accept a tight target or a challenging performance requirement, but that the managers in the treasurer's or comptroller's offices veto the idea. The latter prefer a safer deal with a smaller profit. The notion that businessmen willingly accept risks in order to obtain higher profits has been very commonly believed, but to find actual instances in military procurement is somewhat difficult.

On balance one cannot conclude either that the firms doing defense work are "risk averters" or "risk preferrers." A high risk program may be acceptable if it is covered in a CPFF contract, but in such circumstances, almost by definition, there is no burden of risk on the contractor, for there are no constraints on price and cost. The problem is to find a high risk situation covered by an incentive contract in which there are reasonably tight constraints on price and cost and then to see how firms react. The analysis of cost behavior by itself is inconclusive, for it does not show how efficient the contractor might have been. A cost underrun is evidence of efficiency only if the negotiated targets represent the price that would be arrived at by a competitive process. Unfortunately, that can only be known ex post at best.

This emphasis on the allocation and assumption of risk is appropriate because in most of its major weapon systems the Department of Defense is interested in innovation-the creation of new commodities and new technologies. Innovation is a risky affair and success in it should be appropriately (and highly) rewarded. Schumpeter has noted that:

... enterprise would in most cases be impossible if it were not known from the outset that exceptionally favorable situations are likely to arise which if exploited by price, quality and quantity manipulation will produce profits adequate to tide over exceptionally unfavorable situations. ...

${ }^{9}$ J. A. Schumpeter, Capitalism, Socialism, and Democracy 89-90 (1950). 
Thus it is true that there is or may be an element of genuine monopoly gain in those entrepreneurial profits which are the prizes offered by capitalist society to the successful innovator. But the quantitative importance of that element, its volatile nature and its function in the process in which it emerges put it in a class by itself. ${ }^{10}$

The point made here bears repetition and emphasis. The argument is that economic growth and progress occur because of innovations that are made by entrepreneurs. These innovations are major improvements in the state of the art or technological change. To try to secure such innovations requires sagacity, ingenuity, and a willingness to take risks; and if growth is to be achieved, appropriate rewards must be held out to the innovators. As Schumpeter says, these rewards may resemble "genuine monopoly gain" (a high profit) for they are the "prizes" that reward the successful innovator. Such prizes or monopoly gains will not be in perpetuity and need not be feared on that score, for in the process of creative destruction a new series of innovations will wipe out the profits of the old. Thus progress is achieved; it implies, and is implied by, a high profit level in the progressive industries.

The arguments pro and con for a high level of profits cannot be easily resolved; ultimately they must be justified by a showing of actual superior performance in individual contracts or cases. Profits should not accrue to the efficient and the inefficient equally. That is all the more reason for incorporating performance incentives in contracts and for adopting efficiency classes in incentive contracts so as to establish some reasonable bases for distinguishing and appropriately rewarding superior performance.

Although the demonstration of superior performance must be done contract by contract, we can look at the other side of the question-how well the major aircraft and missile companies have fared in the past in comparison to other industries. The statistics on industry profit levels reveal some interesting contrasts and comparisons.

For the period I950-I959 profit figures of two kinds were computed for twentyeight different industry groups. Profits were computed as a per cent of net worth and as a per cent of sales. The major industry group representing weapon systems contractors were the aircraft companies. The other groups represented primarily manufacturing; but trade, utilities, and mining were also included.

The striking feature in the profit figures is that for this period the aircraft companies ranked first among all industry groups in profit as a per cent of net worth (I6.8 per cent) and twenty-seventh out of twenty-eight in profit as a per cent of sales (3.3 per cent). ${ }^{11}$ On the basis of profits as a per cent of sales the aircraft companies resemble the radio and television broadcasting companies and retail trade, and not other manufacturing companies. The industry groups included electrical machinery, chemicals, and pharmaceuticals in which progress and technological change have been high. Thus the largest contractors in defense have earned profits higher than all other major industries in the economy, including a number that by any standard

${ }^{20} \mathrm{Id}$. at 102 . (Emphasis added.)

${ }^{11}$ MOORE, op. cit. supra note $\mathrm{I}$, at 105. 
would be considered progressive. It should be noted that primary emphasis is on profit as a per cent of net worth, since the net worth figure represents the amount of resources owned by the industry. If the government contribution to resources (i.e., in the form of fixed plant, and so on) were included in the base, the profit percentage would be lower and would fall below some other industries; however, while this consideration is important so far as resource is concerned, the institutional fact is that the profit accrues to private industry. One may infer that the government contribution is under-valued. For judging the efficiency of resource allocation, the ratios of profits on sales are meaningless.

One other comparison can be made using the two profit percentages. The ratios of sales to net worth show how often a company is able to turn over its capital in the course of a year. The turnover ratio is related directly to the profits on sales and profits on net worth by the simple relation:

$$
\frac{\text { Sales }}{\text { Net Worth }}=\frac{\text { Profits }}{\text { Net Worth }} \div \frac{\text { Profits }}{\text { Sales }}
$$

The aircraft group had the highest capital turnover ratio of any of the groups. For this period the turnover ratio was about five; that is, $\$ 5$ of sales were made yearly for every dollar of net worth. Actually the capital turnover ratio for this group has been higher in the past, and has been as high as ten or fifteen, figures that resemble the turnover ratios for chain stores which are purveyors of merchandise and not manufacturing. The continued growth of earned surplus by these companies, since it has added to net worth, has increased the denominator of the turnover ratio so that values of the ratio have been declining. The aircraft companies have been able to do business on a relatively small base of net worth.

Since the price-cost comparison is inconclusive, the criteria for efficiency in defense procurement must rest on the degree of progressiveness and innovation and on the level of profits; yet even these criteria are obscured by the government's role in the internal management of the programs. Profits have been high, and perhaps excessive in the economic sense of the term, on the private resources employed, though not necessarily on total resources employed. It would be a rash critic indeed who would conclude that the level of innovation was not high, though reports on major programs such as the Centaur and Mercury starkly illustrate how inefficient some contractors are, even when the surface impression is one of efficiency and success. ${ }^{12}$ After a perusal of all the evidence, the nagging thought remains that profits have been too high relative to resources committed, that the criteria for distinguishing efficiency from inefficiency have been obscure and imperfectly applied, and that culpability extends to both the government and the contractors. There is still the question of how public policy might effect improvements in the system.

\footnotetext{
${ }^{12}$ See The Comptroller General, of the United States, Review of the Athas-Centaur Launch Veficle Development Program, Report to the House Committee on Science and Astronautics (mimeo., March I963); National Aeronautics and Space Administration, Manned Spacecraft Center, Mercury Project Summary, May I5-16, 1963.
} 
IV

There is a continuous search for ways to improve procurement by the Department of Defense. Since the market operates by negotiation and bargaining rather than through the more generally competitive processes of commercial markets, a good deal of attention is paid to changes in regulations and contractual instruments. There are, of course, a large number of items that the government buys that are the same as those sold in normal commercial channels. On these items the government has great potential advantage since it is a single large buyer dealing (usually) with a large number of sellers. If it chose to do so, the government could drive the price down close to the variable cost of production on such items. In fact, it does not exercise its market power in this way; but the competitive bidding process generally results in low profit margins.

It is sometimes argued that an extension of competitive bidding and fixed price contracts would cure most of the ills of defense procurement; this is usually accompanied by quotation of the statistics showing that the majority of procurement dollars are in contracts with negotiated (that is, non-competitive) prices. No one will quarrel with the argument that competitive bidding is likely to result in favorable cost-price relationships, but this procedure has limited applicability. Competitive bidding and multiple contractors might be employed in research and development work, particularly on components. The amount of money that needs to be allocated to any one contractor is typically small, and the competitive spur would probably result in faster and more efficient performance. Contracting with several firms for work of this kind has not been done because it appears that money is being spent on duplicative work; yet such a criticism can only be the result of misunderstanding the nature of research and development and of competition.

In the procurement of major weapons systems the situation is different. Multiple contracting is infeasible, since the sums involved are large. Competitive bidding is generally limited to the preparation of proposals; and that has limited value because paper studies of complex systems cannot foresee the difficulties that will be encountered once the work is begun. Once a commitment is made, the problem is to design the contract so as to provide incentives for the contractor to be efficient and to eliminate those features that allow poor performance.

There are a number of relatively minor changes in contract procedures (particularly in incentive contracts) that would help sharpen the impact of incentive features. First, a reduction in the delay in setting firm targets is desirable. In a sample of incentive contracts delays of one to two years was typical; and in some cases the number of months between the initial targets and the firm targets was greater than the number of months from the setting of firm targets to the end of the contract. Such delays in setting firm targets simply tend to confirm what the contractor has done and hence vitiate the incentive feature. Second, there is relatively little dispersion in profit rates in incentive contracts; this exists because the basic negotiated profit rate (typically seven to eight per cent) acts as a cushion and 
the incentive feature in the sharing formula does not "swing" the rate very much. The result is that a (relatively) inefficient producer may earn six to seven per cent and a (relatively) efficient one eight to nine per cent. The difference may be so small as to make it unprofitable to take steps to watch cost effectively. A further point along this same line lies in the preference for 80-20 sharing formulae. This is the most common formula used; yet under some circumstances formulae such as 50.50 or even 40-6o would achieve much more. Because of uncertainty in cost estimates one can argue that there should be no sharing for cost differentials within, say, five per cent of the target cost; this would result in a variable price to the government. Beyond that range a 50-50 sharing offers an incentive that is likely to have a real impact on contractor performance. Moreover, in other circumstances there are possibilities of exploiting asymmetrical formulae (i.e., different sharing for cost overruns and underruns)

There is an increasing tendency to include various performance incentives, as well as cost incentives, in the contracts. Profits then depend on meeting or exceeding objectives with respect to reliability, delivery dates, test performance, and other measures. A given total profit can be realized by various combinations of performance on these objectives, but some combinations may be easier to achieve than others, and the government may not be indifferent as among the combinations. This can only be avoided by taking care with the profit differentials assigned to each performance objective. There are, in short, trade-offs among the objectives, and these trade-offs can be calculated to show the effect on profits and costs. In some past contracts the profit differentials have weighted one objective, say delivery date, so heavily that a slip of a very few months would be heavily penalized whereas missing on the objectives of reliability or test results would cause little change in profits. Obviously a shrewd contractor can calculate these trade-offs and choose the combination that is easiest to attain. This would also be acceptable to the government if every such combination yielding the same profit were equally desirable; however, some of the performance incentive contracts contained weights for different objectives that resulted in very strange implicit values for different combinations. Since the use of performance incentives is an important way to improve contract outcomes, the trade-offs among objectives and the profit weights associated with them need to be examined more closely than they have been in the past.

There is one further fundamental modification to incentive contracts that, in some circumstances, might be very effective, and that is the establishment of multiple efficiency classes. At present a single target is set for each of the objectives and incentives are then attached to surpassing the target. There is evidence that cost targets may be loose and relatively easy to surpass. An alternative is to set "hard targets" on cost and perhaps on other objectives after the initial negotiation of these targets. These "hard targets" could be set unilaterally by the government and would require markedly improved performance by the contractor. For ex- 
ample, if the original cost target was Ioo, the "hard target" might be set at 90 . One or more efficiency classes can be established in this way. The contractor can then be given a choice of efficiency classes. If he chooses a hard one, he may look forward to substantially higher profits than if he chooses an easy one; and he would be no worse off if his performance fell between the hard and easy targets. Moreover, if the easy target was consistently chosen by the contractor, that in itself would be an indication of an unwillingness to take risks and to bet on his ability to perform.

Very recently, in Armed Services Procurement Regulation 3-808, ${ }^{13}$ the Department of Defense has adopted a system that provides guidelines to weight profits for each of a number of specific categories (e.g., materials, engineering labor, and so forth), and weights are also assigned to the past performance of the contractor and to the initiative of the contractor in undertaking development with his own funds. This represents a significant step in the direction of putting emphasis on performance and on the assumption of risk by the contractor. It is still too early to say how the new system will work in practice; the profit weights may have to be revised later. But this is a hopeful step.

Improvements in incentive provisions and in contractual instruments are necessary to a re-stimulation of contractor responsibility and necessary if we are to obtain a test of contractor performance; but they are not sufficient. It is time to take steps to sever, in part, the "dancing partners," to disengage the government from much of its involvement in the internal decision-processes of the company and to make the contractor dance alone to see how well he can do. So long as government supplies plant and equipment and in other ways assumes responsibility for decisions, the contractor has a crutch on which to lean. To correct this some greater share of risk and responsibility must be assumed by the contractor. This does not mean that the government can or should abdicate all responsibility; there is too much at stake for that. There is a need for a strong project office and for cost control and review of technical milestones in the programs. At the same time there can be a relaxation of other controls: by way of example, the number of reports can be decreased and the number of echelons through which decisions must be filtered and approved can be cut. The government should retain control over total costs and be tougher on overruns, but at the same time allow the contractor greater flexibility in the allocation of resources within the total, so that the contractor might choose to spend less on quality control, engineering design and drawings, subcontracting, tooling, or the completeness of design. To allow this, however, also requires freezing on performance specifications early so that the job to be done is well known. If the specifications are frozen in a few major areas and proposed engineering changes are resisted, the contractor has freedom to try alternative methods in some areas while still assuring that the major objectives are met. At the same time the probability of getting an operational system soon is enhanced.

\footnotetext{
${ }^{18}{ }_{32}$ C.F.R. $\$ 3.808$ (Supp. 1963 ).
} 
The addition of requirements, performance objectives, and personnel is no guarantee of improved or faster response; in fact the reverse is more likely.

In a brief paper it is not possible to be very specific about the exact form of the changes. Circumstances of each program generally require special adaptation; however, the directions for disengagement are fairly clear. The lessons that might be learned from the development of the $U_{-2}$ (and of certain other systems) have not been sufficiently appreciated.

Some persons instinctively reject the notion of a disengagement of government from intimate control of programs. Those who do so generally point to the uncertainties involved in weapon systems development and to the stake we have in an effective defense system. They argue that greater rather than less government control is needed; but the full implications of such a position are usually not pursued. There has been loose discussion of the aircraft and missiles industry as a "captive" industry. There is no doubt that most of the growth of the industry is attributable to government contracts. But greater government control certainly means some change in the present institutional arrangements, possibly leading to a de facto nationalization of the industry with effective control by the government. Alternatively this approach might lead to a public utility concept for the industry; but in that case innovation would rest solely in the hands of the government. These are issues that have not been thoroughly examined; yet the problems they pose for public policy are immense. Before any greater government control is adopted, it is essential to look carefully at the costs and benefits of pursuing such a policy. Greater control is probably inconsistent with the existing framework; it implies major changes of a kind that we now only dimly perceive.

It is possible that the existing framework of government-industry relations will persist with minor improvements through changes in contracting; that also means accepting the many imperfections of the system. A movement toward disengagement is an attempt to introduce a greater degree of responsibility and competitiveness in the market. A movement toward greater government control probably means major institutional and legal changes in the system. At this point the choices for public policy are not at all clear; the major issues and potential outcomes need, above all, a thorough examination. 